\title{
Optimization Design of the Composite Structure of Linear Motor Machine Tools
}

Tzu-Chi Chan, Yu-Ping Hong, Yu-Chuan Wang and Shang-Hung Wu

Department of Mechanical and Computer-Aided Engineering, National Formosa University, No. 64, Wenhua Rd Huwei Township, Yunlin County 632, Taiwan (R.O.C.)

\begin{abstract}
Owing to the increasing demand for improvement in production efficiency, there has been rapid development in the structure of the machine tool. Linear motors are used in machine tool feed systems, significantly improving their speed, acceleration, and accuracy. Additionally, the traditional machine tools have undergone structural changes. In this study, the polymer concrete structure of a linear motor machine tool is examined, including the static and dynamic characteristics analysis. This study adopted the finite element analysis (FEA) method to analyze the entire machine structure to improve the deformation and resonance of the machine tool. The FEA method was applied to machine tools in the design process, including static deformation analysis, modal analysis, transient analysis, and harmonic analysis. We conducted an analysis of the deformation of the machine caused by gravity acceleration and the cutting force by exploring the main factors that affect the cutting process of the machine. To further analyze the influence of vibrations on the processing quality, a transient response analysis was conducted, and the effect of the axial cutting force during machining was discussed. Furthermore, the harmonic analysis of the machine was performed. Finally, we optimized the structural design of the machine tool to eliminate unnecessary materials to reduce its weight.
\end{abstract}

Key words: Finite element method, machine tool, polymer concrete, linear motor, optimization design.

\section{Introduction}

The technical performance of a machine tool is regarded as a vital indicator of national industrialization. This study mainly uses composite materials as the linear motor tool machine structure for analysis. In this study, the finite element method is used to analyze the static and dynamic characteristics of the whole machine tool structure, and the structural deformation and vibration of the machine tool are analyzed. The research steps are illustrated in Fig. 1. The rate of temperature rise of the wafer in a specified duration is determined.

This study mainly discusses the structure of a horizontal machine tool, including the static and dynamic characteristics analysis. The finite element analysis (FEA) method is used to analyze the whole machine structure and improve the deformation and

Corresponding author: Tzu-Chi Chan, Ph.D., research fields: precision machine design, finite element analysis and testing, smart manufacturing system. resonance of the horizontal machine tool. In this study, the FEA method was applied to the design process of the machine tool, including the static deformation analysis, modal analysis, transient analysis, and harmonic analysis of the machine.

Some studies on FEA methods of static and dynamic deformation analysis in manufacturing processes have been reported. Li et al. [1] compared the dynamic performance of two 3-DOF parallel manipulators, proposed a novel optimization method for the counterweight masses for the development of a new hybrid machine tool. Wu et al. [2] investigated the mechatronics modeling and forced vibration of a 2-DOF parallel manipulator in a 5-DOF hybrid machine tool. Ericson and Parker [3] applied the experimental modal analysis to characterize the planar dynamic behavior of two spur planetary gears. Ohta and Hayashi [4] studied the vibration of a linear guideway type (LGT) recirculating linear ball bearing driven at a constant 


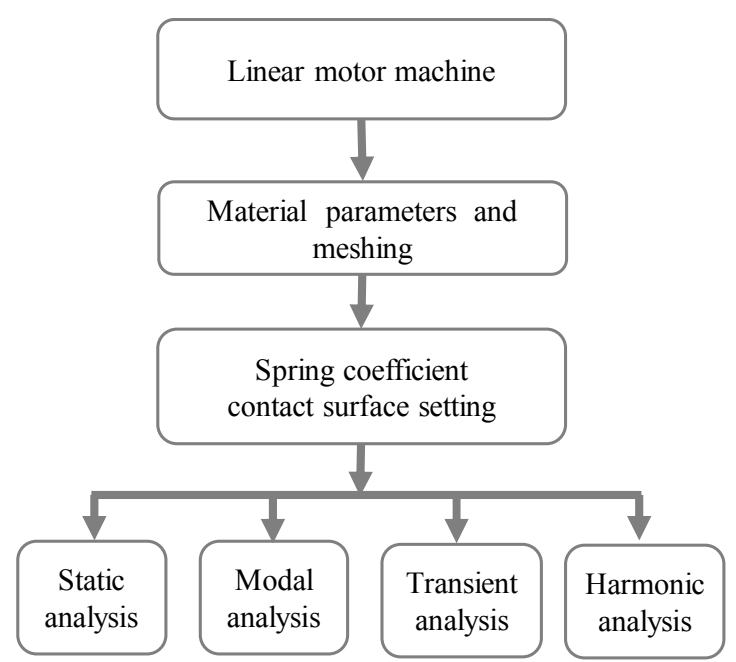

Fig. 1 Flow chart of research.

linear velocity. Simon [5] applied the thermal analysis of lubrication to investigate the influence of the machine tool setting for pinion tooth finishing on lubrication in hypoid gears. Whalley et al. [6] derived the $\mathrm{X}-\mathrm{Y}$ axes, distributed-lumped model, for a machine tool system. Model validations using measured results were presented. Wu et al. [7] reported the stiffness of a 5-DOF hybrid machine tool with actuation redundancy. Zhou et al. [8] demonstrated that because the machined surface is part of the cutter envelope surface generated by the cutter motion, it is necessary to calculate the envelope surface to obtain the geometric deviation. Gegg et al. [9] proposed a simplified mechanical model for a machine-tool system. The state and domains were defined for the boundaries in this system.

In this study, the FEA method is used to analyze the static and dynamic characteristics of the whole machine tool structure, and the structural deformation and vibration of the machine tool are analyzed.

The rest of this paper is organized as follows: Section 2 explains the analysis method; Section 3 introduces the optimization methods; Section 4 presents the conclusions.

\section{FEA Method}

First, we import the CAD drawings into the software and then build the model. Next, we set the material properties of the materials used, including cast steel and polymer concrete, and then mesh the model. Furthermore, we perform FEA using software to explore the structural characteristics of the machine tool. The CAD model used in this study is illustrated in Fig. 2.

\subsection{Material Properties}

The materials used in the linear motor machine tool include cast steel and polymer concrete. The material properties are listed in Tables 1 and 2. The finite element model of a linear motor machine tool is shown in Fig. 3.

\subsection{Finite Element Boundary Condition Setting}

The machine tool has many combined interfaces. The linear motion mainly uses a linear guideway. A couple simulates the contact between the slider and linear guideway as shown in Fig. 4. The fixing method of the relevant interface is based on the actual machine combination setup. The linear motor machine tool boundary conditions are as shown in Fig. 5.

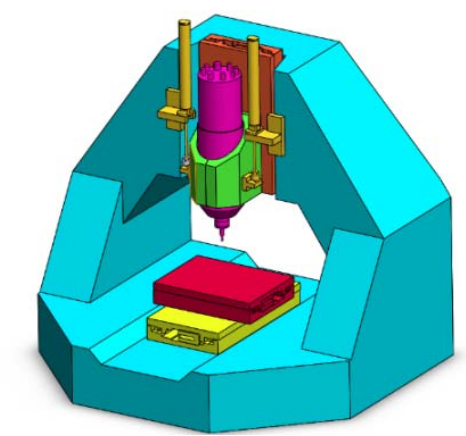

Fig. 2 Linear motor machine tools model.

Table 1 Properties of cast steel materials.

\begin{tabular}{ll}
\hline \multicolumn{2}{c}{ Cast steel materials } \\
\hline Density $\left(\mathrm{kg} / \mathrm{m}^{3}\right)$ & 7,850 \\
Young's modulus $(\mathrm{Pa})$ & $2 \mathrm{e}+11$ \\
Poisson's ratio & 0.3 \\
\hline
\end{tabular}

Table 2 Properties of polymer concrete.

\begin{tabular}{lc}
\hline \multicolumn{2}{c}{ Polymer concrete } \\
\hline Density $\left(\mathrm{kg} / \mathrm{m}^{3}\right)$ & 2,800 \\
Young's modulus $(\mathrm{Pa})$ & $1.4 \mathrm{e}+11$ \\
Poisson's ratio & 0.2 \\
\hline
\end{tabular}




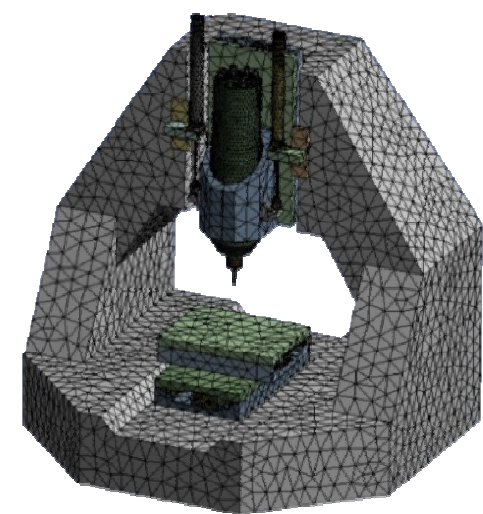

Fig. 3 Finite element model of a linear motor machine tool.

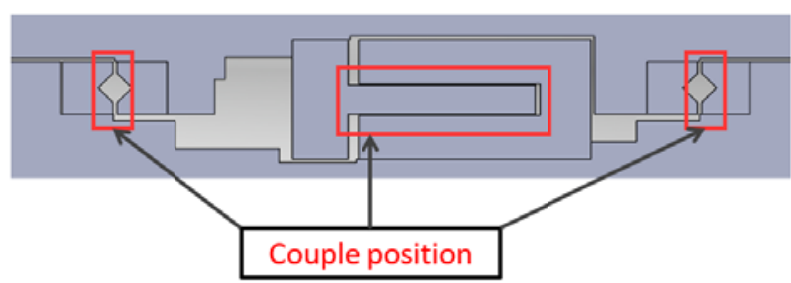

Fig. 4 Linear guideway contact by a couple.

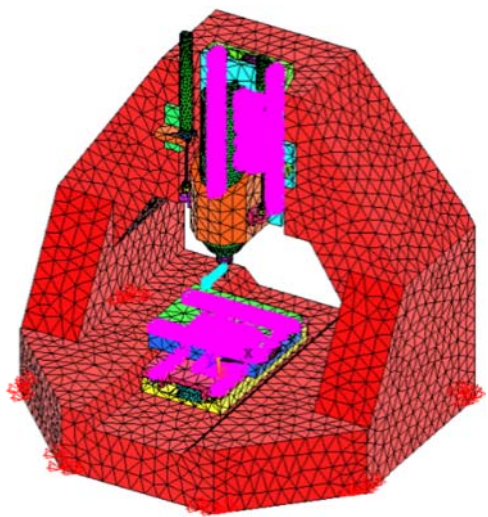

Fig. 5 Linear motor machine tool boundary conditions.

\subsection{Simulation Results}

The acceleration of gravity is $9.8 \mathrm{~m} / \mathrm{s}^{2}$. The simulated machine is subjected to a force of $-50 \mathrm{~N}$ during machining, applied in the Z-axis direction at the knife holder of the tool. It can be seen from the analysis results that a significant deformation occurs at the spindles and the worktable, and the maximum deformation is $3.66 \mu \mathrm{m}$. The static stiffness analysis results are depicted in Fig. 6.

\subsubsection{Modal Analysis}

Using the finite element method to analyze the dynamic structure of the machine tool, the analysis frequency range is found to be $1-1,000 \mathrm{~Hz}$. From the modal analysis results, the vibration mode and natural frequency of the machine are obtained. The first mode shape's natural frequency is $409.5 \mathrm{~Hz}$, second mode shape's natural frequency is $510.4 \mathrm{~Hz}$, and third mode shape's natural frequency is $637.3 \mathrm{~Hz}$. These three mode shapes are depicted in Figs. 7-9.

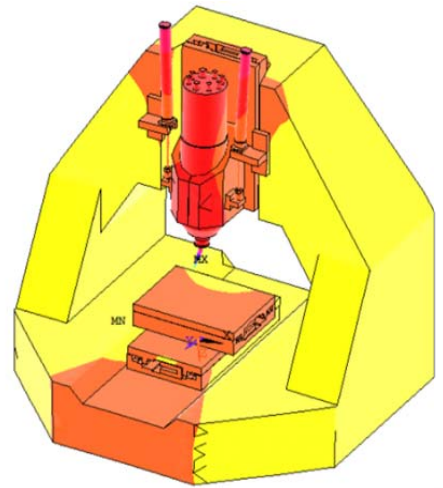

Fig. 6 Static rigidity analysis of linear motor machine tool.

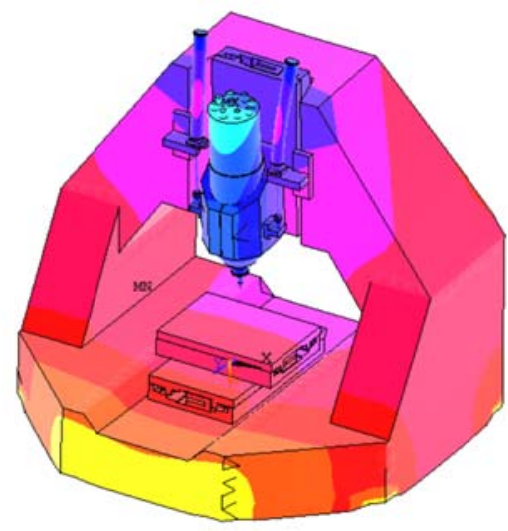

Fig. 7 First mode shape $(409.5 \mathrm{~Hz})$.

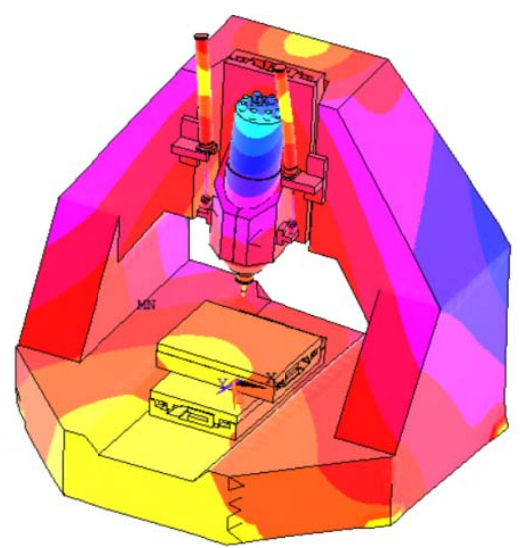

Fig. 8 Second mode shape $(510.4 \mathrm{~Hz})$. 


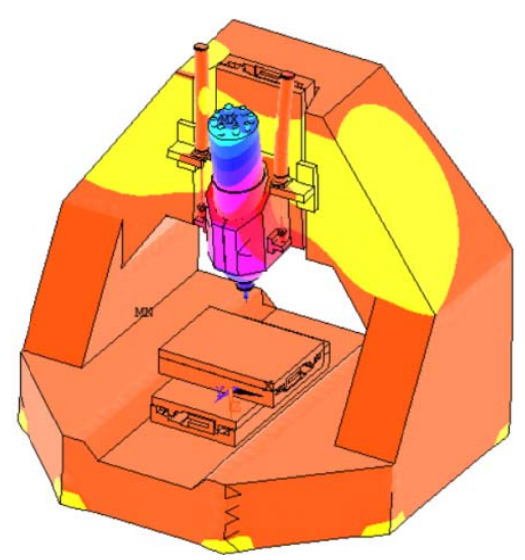

Fig. 9 Third mode shape (637.3 Hz).

\subsubsection{Cutting Transient Analysis}

The transient analysis of the impact force is found to be $50 \mathrm{~N}$. The fixed point is located at the base, and the impact shank of the impact force at the tool for analysis is depicted in Fig. 10. After the simulated cutting impact load is applied for $0.05 \mathrm{~s}$, the force responds to the vibration phenomenon within $3 \mathrm{~s}$. From the results depicted in Fig. 11, the amplitude of the transient response in the $\mathrm{X}$-axis direction of the tool shank can be obtained.

\subsubsection{Harmonic Analysis}

Damping is an essential factor in dynamic performance. If the damping value is high, the vibration amplitude is small. In the harmonic analysis of this study, the stiffness damping ratio of the harmonic analysis is 0 and 0.003 . The natural frequency and vibration

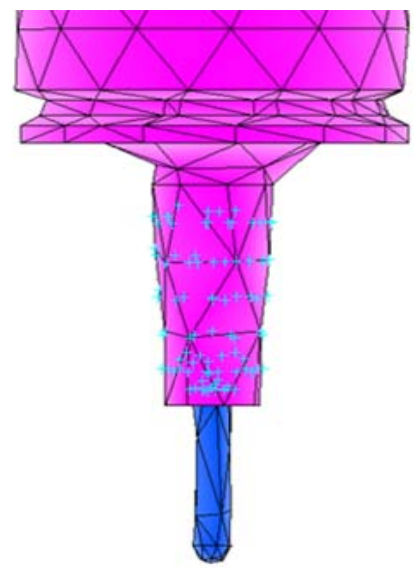

Fig. 10 Cutting point of cutting force.

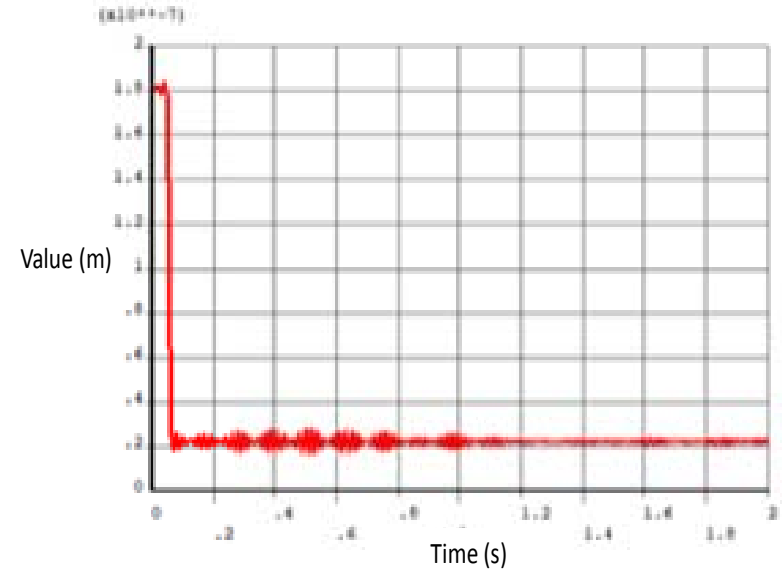

Fig. 11 Transient response analysis in $\mathrm{X}$ direction.

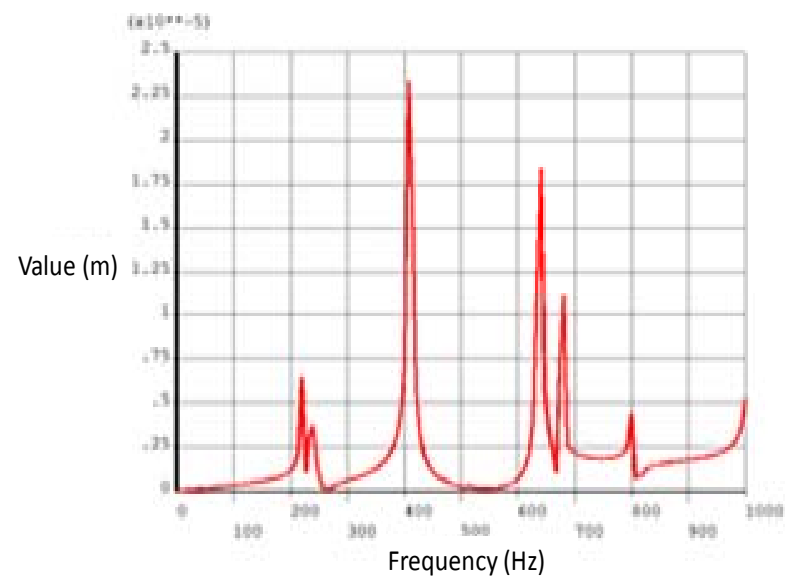

Fig. 12 Damping ratio is 0, harmonic analysis in $\mathrm{Y}$ direction.

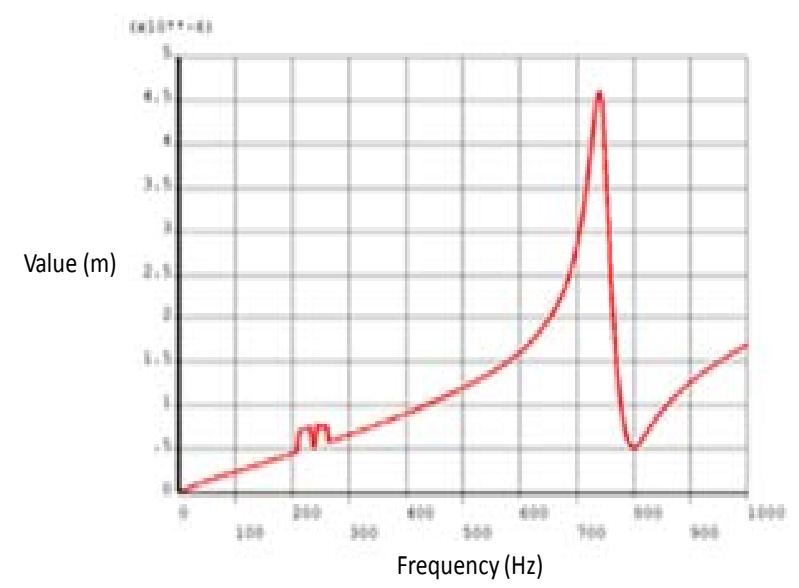

Fig. 13 Damping ratio is 0.003 , harmonic analysis in $\mathbf{Y}$ direction.

amplitude in the $\mathrm{Y}$ direction of the linear motor machine are compared in Figs. 12 and 13. Further analysis of the dynamic characteristics of the results reveals that the vibration amplitude is significantly reduced. 


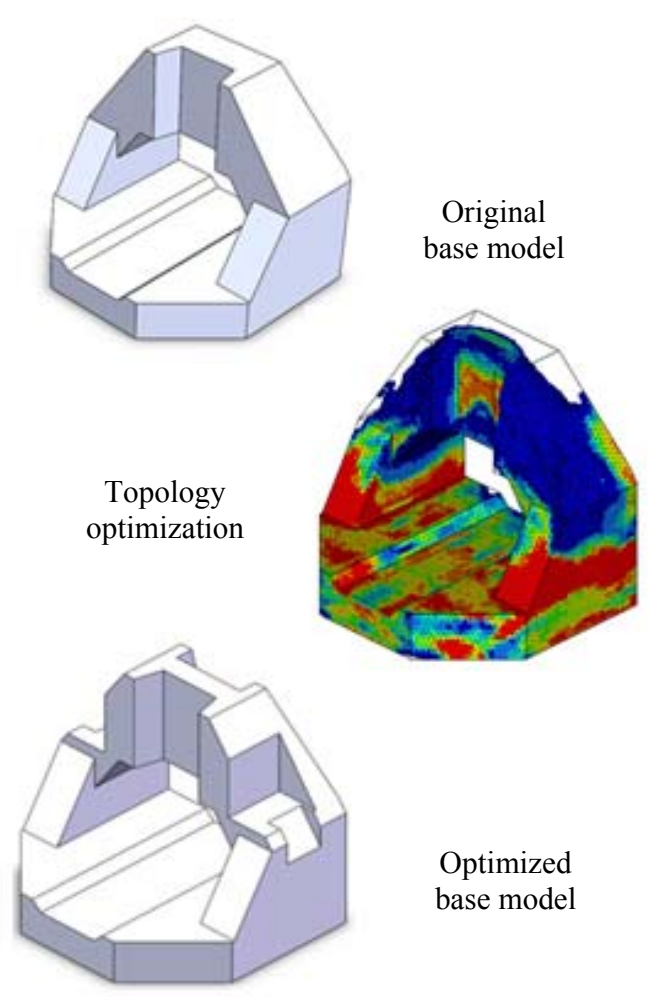

Fig. 13 Structural optimization analysis results.

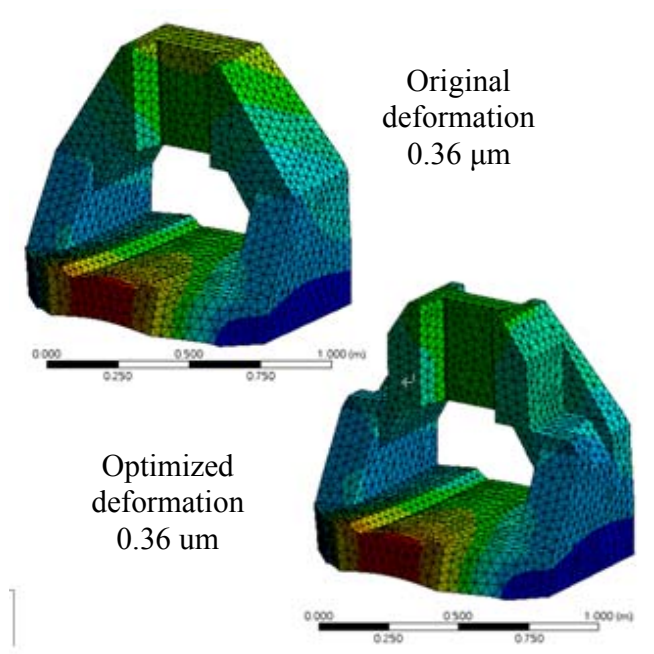

Fig. 14 Structural optimization deformation analysis results.

\section{Optimization Design}

Topology optimization is used to reduce the weight of the structural material depicted in Fig. 14. The optimization objective of this experiment is mainly to reduce the weight of the base material by the largest volume of the structural materials. The original structural weight is $591.6 \mathrm{~kg}$, and the structural weight after analysis is $547.0 \mathrm{~kg}$; thus,

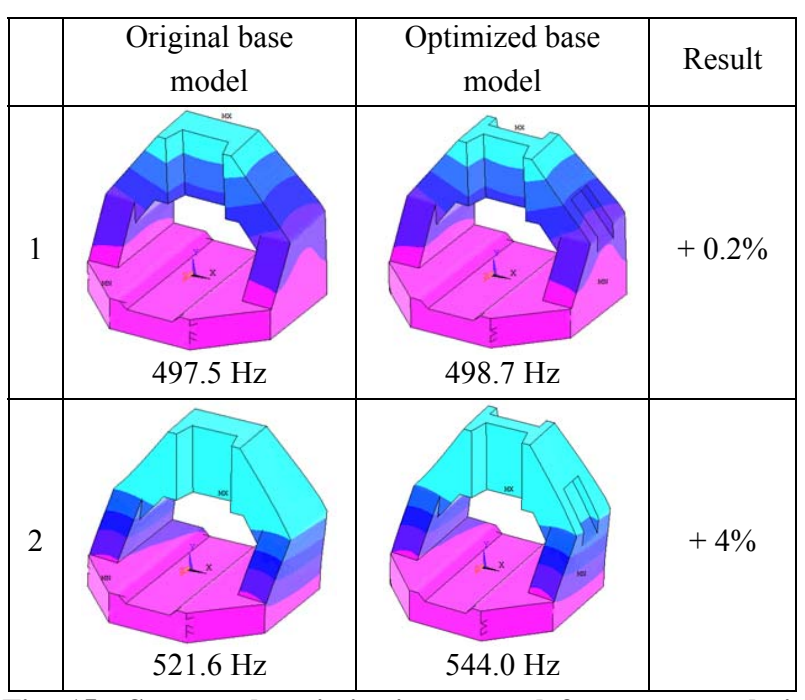

Fig. 15 Structural optimization natural frequency analysis results.

the total material weight is reduced by $7 \%$. It can be seen from the analysis results that a large deformation occurs at the main shaft and base, and the maximum deformation is $0.36 \mu \mathrm{m}$ as shown in Fig. 15 .

\section{Conclusions}

Because of the rapid development of the machine tool industry, the accuracy, efficiency, and delivery requirements of the machine tool are crucial. Therefore, the technology of the machine tool design analysis is particularly important. It is essential to analyze the static and dynamic characteristics of the machine structure during the design to understand the machine tool's structural deformation and dynamic performance. In this study, the FEA method is used to analyze the static and dynamic characteristics of the whole structure. Topology optimization is also used to reduce the structural weight and improve the structural characteristics of the machine. Furthermore, the actual machining conditions of the machine tool are simulated. When $-50 \mathrm{~N}$ is applied in the Z-axis direction at the shank portion, static stiffness analysis is performed, and the maximum deformation is found to be $3.44 \mu \mathrm{m}$. Modal analysis is used to determine the natural frequency and mode shape of the structure. In the transient analysis, the frequency and amplitude of the vibrations are examined to understand the dynamic 
response of the machine tool. Moreover, transient analysis demonstrates the responses of important locations in the machine structure. We employ the above analysis to improve the static and dynamic characteristics of the entire machine and optimize the base topology to reduce its weight. It is shown that the total material weight can be reduced by $7 \%$, and the original static stiffness can be achieved while increasing the frequencies of the modes.

\section{Acknowledgements}

The authors are greatly indebted to the Ministry of Science and Technology of the R.O.C. for supporting the research (grant number: MOST 107-2218-E-150-005-MY3). The authors are greatly indebted the Precision Machinery Research and Development Center.

\section{References}

[1] Li, Y.-W., Wang, J.-S., Liu, X.-J., and Wang, L.-P. 2010. "Dynamic Performance Comparison and Counterweight Optimization of Two 3-DOF Parallel Manipulators for a New Hybrid Machine Tool." Mechanism and Machine Theory 45 (11): 1668-80.

[2] Wu, J., Yu, G., Gao, Y., and Wang, L.-P. 2018. "Mechatronics Modeling and Vibration Analysis of a
2-DOF Parallel Manipulator in a 5-DOF Hybrid Machine Tool." Mechanism and Machine Theory 121: 1339-51.

[3] Ericson, T.-M., and Parker, R. G. 2010. "Planetary Gear Modal Vibration Experiments and Correlation against Lumped-Parameter and Finite Element Models.” J. Sound Vib. 50: 156-64.

[4] Ohta, H., and Hayashi, E. 2000. "Vibration of Linear Guideway Type Recirculating Linear Ball Bearings." J. Sound Vib. 235: 847-61.

[5] Simon, V. 2009. "Influence of Machine Tool Setting Parameters on EHD Lubrication in Hypoid Gears." Mechanism and Machine Theory 44 (5): 923-37.

[6] Whalley, R., Abdul-Ameer, A. A., and Ebrahimi, K. M. 2011. "The Axes Response and Resonance Identification for a Machine Tool." Mechanism and Machine Theory 46 (8): 1171-92.

[7] Wu, J., Wang, J.-S., Wang, L.-P., Li, T., and You, Z. 2009. "Study on the Stiffness of a 5-DOF Hybrid Machine Tool with Actuation Redundancy." Mechanism and Machine Theory 44 (2): 289-305.

[8] Zhou, Y.-S., Chen, Z.-C., and Yang, X.-J. 2015. “An Accurate, Efficient Envelope Approach to Modeling the Geometric Deviation of the Machined Surface for a Specific Five-Axis CNC Machine Tool." International Journal of Machine Tools and Manufacture 95: 67-77.

[9] Gegg, B. C., Suh, S. C. S., and Luo, A. C. J. 2010. "Modeling and Theory of Intermittent Motions in a Machine Tool with a Friction Boundary." Journal of Manufacturing Science and Engineering, Transactions of the ASME 132 (4): 0410011-9. 